\title{
Detecção de locos de características quantitativas nos cromossomos 1, 2, 3, 12, 14, 15 e X de suínos: características de desempenho
}

\author{
[Detection of quantitative trait loci on chromosomes 1, 2, 3, 12, 14, 15, X in pigs: \\ performance characteristics] \\ D.M. Paixão ${ }^{1}$, J. Braccini Neto ${ }^{2}$, S.R. Paiva ${ }^{3}$, P.L.S. Carneiro $^{2}$, A.P.G. Pinto ${ }^{1}$, K.R.S. Sousa ${ }^{1}$, \\ C. Souza do Nascimento ${ }^{1}$, L.L. Verardo ${ }^{1}$, A.M. Hidalgo ${ }^{1}$, P.S. Lopes $^{4}$, S.E.F. Guimarães ${ }^{4 *}$ \\ ${ }^{1}$ Aluno de pós-graduação - Universidade Federal de Viçosa - Viçosa, MG \\ ${ }^{2}$ Aluno de pós-doutorado - Universidade Federal de Viçosa - Viçosa, MG \\ ${ }^{3}$ Empresa Brasileira de Pesquisa Agropecuária - Brasília, DF \\ ${ }^{4}$ Universidade Federal de Viçosa - Viçosa, MG \\ RESUMO
}

\begin{abstract}
Mapeou-se quantitative trait loci (QTL) associados a características de desempenho nos cromossomos 1, 2, 3, 12, 14, 15 e X de suínos pertencentes a uma população F2, formada a partir do cruzamento entre dois machos da raça naturalizada brasileira Piau e 18 fêmeas comerciais (Landrace x Large White x Pietrain). O mapa genético de ligação da população foi construído após a genotipagem dos animais para 35 marcadores microssatélites. As estimativas do conteúdo de informação polimórfica indicaram que os marcadores microssatélites foram adequados para as análises de QTL. Os dados foram analisados pelo mapeamento por intervalo usando-se o programa GridQTL. Encontraram-se seis QTL, sendo que o QTL genômico para idade ao abate atingiu a significância de 5\% de probabilidade. As informações dos QTL detectados neste estudo são úteis para identificar genes que podem ser usados em conjunto com os métodos convencionais de seleção, aumentar a acurácia deles e prover uma compreensão dos fenótipos produtivos de suínos.
\end{abstract}

Palavras-chave: raça Piau, marcador molecular, nível genômico, suíno

\begin{abstract}
The accomplishment of the present study had the objective of mapping Quantitative Trait Loci (QTL) related to performance traits in a F2 pig population developed by mating two Brazilian Piau breed sires with 18 dams from a commercial line (Landrace $\times$ Large White $\times$ Pietrain). The linkage map for this population was constructed after genotyping the animals for 35 microsatellite markers. Estimates of polymorphic information content indicated that the microsatellite markers were appropriate for QTL analyses. The genotypes were analyzed by interval mapping using the GridQTL program. A total of six QTL were found, of which the QTL for slaughter age (days) was significant at the 5\% genome-wise level. The information of the significant QTL detected in this study is useful for future fine-mapping studies for the identification of genes. Such information can be used together with traditional methods in breeding programs or even for a better understanding of the phenotypes of swine production.
\end{abstract}

Keywords: Piau breed, marker molecular, genome-wise, pig

Recebido em 7 de abril de 2011

Aceito em 20 de setembro de 2012

*Autor para correspondência (corresponding author)

E-mail: sfacioni@uvf.br

Apoio financeiro: CAPES, CNPq, FAPEMIG e INCT - Ciência Animal 


\section{INTRODUÇÃO}

As características de crescimento, consumo e conversão alimentar têm grande importância para a indústria de suínos, uma vez que $70 \%$ dos custos de produção dos animais são com alimentação; contudo, a arquitetura genética associada a essas características é ainda pouco conhecida. Selecionar reprodutores para formar um sistema eficiente de produção na suinocultura é um dos objetivos dos programas de melhoramento. Nesse sentido, a identificação de locos e/ou genes que influenciam características economicamente importantes pode resultar em maior resposta à seleção e consequentemente em maiores ganhos econômicos na suinocultura.

A varredura genômica é um método que tem demonstrado ser bastante efetivo na localização de regiões envolvidas na expressão de características de interesse econômico nos animais domésticos. Em suínos, um grande número de quantitative trait loci (QTL), ou seja, associação estatística significativa entre os valores genotípicos e a variabilidade fenotípica na progênie segregante, tem sido identificado usando-se intercruzamento entre populações divergentes (Pires et al., 2005; Silva et al., 2008; Paixão et al., 2008a,b; Gilbert et al., 2010).

A raça naturalizada brasileira Piau, cujo nome significa "pintado" na língua indígena de onde é derivada (Tôrres, 1968), foi originada a partir dos primeiros suínos, pertencentes às raças da Península Ibérica, trazidos pelos colonizadores portugueses. Segundo Guimarães e Lopes (2001), as características principais desses animais são a rusticidade, a adaptabilidade às condições precárias de manejo e alimentação e a grande resistência a doenças. Além disso, a raça é caracterizada por baixa produção, tamanho pequeno da leitegada e grande acúmulo de gordura subcutânea.

O presente trabalho foi realizado com os objetivos de detectar QTL para características de crescimento, conversão alimentar e número de tetas nos cromossomos 1, 2, 3, 12, 14,15 e X de uma população $F_{2}$ de suínos, formada a partir do cruzamento entre machos da raça Piau e fêmeas pertencentes a uma linhagem comercial, e concluir, dessa forma, o mapeamento dos 18 cromossomos autossômicos e do cromossomo sexual X nessa população.

\section{MATERIAL E MÉTODOS}

Uma população experimental composta por três gerações foi desenvolvida na Granja de Melhoramento de Suínos do Departamento de Zootecnia da UFV, em Viçosa, MG, no período de novembro de 1998 a julho de 2001. Os animais F2 foram originados a partir do cruzamento entre dois varrões da raça naturalizada brasileira Piau e 18 fêmeas de uma linhagem comercial (Landrace $\mathrm{x}$ Large White $\mathrm{x}$ Pietrain) selecionada para características de desempenho. Na geração F1, 11 machos e 54 fêmeas, não aparentados, foram acasalados ao acaso.

Os animais foram pesados ao nascimento e desmamados aos 21 dias de idade. Após o desmame, receberam ração comercial ad libitum . Dos 77 aos 105 dias de idade foram mantidos em baias individuais, e o consumo de ração (CR), a conversão alimentar (CA) e o ganho de peso diário (GPD) foram medidos. Os animais foram abatidos no momento em que atingiram, aproximadamente, $65 \mathrm{~kg}$, correspondendo a 148 dias de idade.

O DNA dos 20 animais parentais, 64 F1 e 400 F2, foi extraído do sangue coletado imediatamente após o abate, utilizando-se o método de extração por precipitação com sal (Miller et al., 1988). As soluções de DNA para uso foram diluídas na concentração de $25 \mathrm{ng} / \mu \mathrm{L}$, em solução de Tris_EDTA (Tris-HCL 10mMpH 8,0 e EDTA 1mM- pH 8,0), e foram mantidas em geladeira a $4^{\circ} \mathrm{C}$. A subsequente análise do DNA genômico foi feita no Laboratório de Genética Animal da Embrapa Recursos Genéticos e Biotecnologia, Brasília, DF.

Os primers de microssátelites foram doados pelo coordenador do US Pig Genome (supported by the USDA-Cooperative State Research, Education, and Extension Service through National Research Support). O conjunto inicial dos marcadores microssátelites foi testado em relação a sua amplificação e informatividade, sendo selecionados 35 marcadores para mapear o genoma dos animais. As amplificações dos 484 animais foram feitas em termocicladores MJ Research PTC 100-96, utilizando-se QIAGEN Multiplex PCR kit (Qiagen, Valencia, CA, EUA). O escoreamento dos fragmentos 
amplificados foi feito usando-se o software GenScan (Applied Biosystems, Foster City, CA, EUA) por meio de sequenciador automático $\mathrm{ABI}$ PRISM 3700.

A determinação da informação contida em cada loco, bem como o grau de polimorfismo d (PIC), foi computada por meio do software CERVUS, versão 3.0 (Kalinowski et al., 2007). Para construção do mapa de ligação dos seis cromossomos autossômicos e o cromossomo sexual $\mathrm{X}$, utilizou-se o software CRIMAP, versão 2.4 (Green et al., 1990).

Os dados de genótipos, fenótipos e o mapa de ligação gerados foram submetidos ao software GridQTL (Seaton et al., 2006) para detecção de QTL. No modelo estatístico utilizado, assumiuse que o QTL é dialélico e com alelos alternativos fixados em cada raça parental. A probabilidade de cada indivíduo F2 apresentar cada um dos três genótipos do QTL é calculada conforme o genótipo dos marcadores, a intervalos de $1 \mathrm{cM}$ ao longo do cromossomo. Funções dessas probabilidades são usadas para se fazer a regressão das características nos coeficientes aditivos e de dominância do QTL em estudo, para cada animal, como descrito por Haley et al. (1994). Foram avaliadas 12 características de desempenho; maiores detalhes sobre essas características e as análises estatísticas foram descritos por Paixão et al. (2008a,b).

A determinação dos limiares de significância cromossômica $(\mathrm{Pc}<0,05$ e $\mathrm{Pc}<0,01)$ foi feita no software GridQTL, com 10.000 permutações (Churchill e Doerge, 1994). Os limiares genômicos foram obtidos por meio da correção de Bonferroni (Knott et al., 1998). O intervalo de confiança a $95 \%$ (IC95\%) para a localização do QTL foi obtido usando-se a aproximação de quiquadrado. A fração aditiva da variância fenotípica $\left(\mathrm{h}_{\mathrm{q}}^{2}\right)$ explicada por determinado QTL foi calculada conforme descrito por Pérez-Enciso et al. (2000).

\section{RESULTADOS E DISCUSSÃO}

Os 35 marcadores utilizados na varredura cromossômica foram classificados como moderadamente polimórficos $(0,25>\mathrm{PIC}>0,5)$ ou altamente polimórficos (PIC $>0,5)$ (Botstein et al., 1980), sendo considerados eficientes para estudos de características quantitativas na população em estudo, uma vez que a aplicabilidade dos marcadores, em varreduras cromossômicas/genômicas, possui relação direta com o seu grau de polimorfismo (Tab. 1).

Tabela 1. Posição dos marcadores no cromossomo, número de alelos segregando para cada marcador (alelos) e conteúdo de informação polimórfica (PIC) para cada marcador

\begin{tabular}{ccccc|ccccc}
\hline Marcador & Chr $^{1}$ & Pos $^{2}$ & Alelos & PIC & Marcador & Chr $^{1}$ & Pos $^{2}$ & Alelos & PIC \\
\hline SW781 & 1 & 55 & 3 & 0,44 & SW1962 & 12 & 91 & 4 & 0,60 \\
SW2035 & 1 & 71 & 4 & 0,60 & S0106 & 12 & 113 & 7 & 0,81 \\
S0113 & 1 & 80 & 3 & 0,54 & SW857 & 14 & 0 & 7 & 0,78 \\
SWR982 & 1 & 84 & 3 & 0,56 & SW210 & 14 & 45 & 6 & 0,56 \\
S0112 & 1 & 120 & 4 & 0,63 & SW761 & 14 & 86 & 4 & 0,44 \\
SW2423 & 2 & 0 & 6 & 0,79 & SW2515 & 14 & 125 & 5 & 0,48 \\
SW240 & 2 & 48 & 7 & 0,70 & S0355 & 15 & 0 & 4 & 0,43 \\
SW395 & 2 & 70 & 5 & 0,66 & S0004 & 15 & 29 & 3 & 0,39 \\
SW1883 & 2 & 98 & 3 & 0,35 & SW1989 & 15 & 64 & 6 & 0,69 \\
S0036 & 2 & 150 & 4 & 0,67 & SW1316 & 15 & 88 & 5 & 0,71 \\
SW2021 & 3 & 0 & 6 & 0,75 & SW936 & 15 & 100 & 5 & 0,74 \\
S0206 & 3 & 39 & 5 & 0,59 & SW1262 & 15 & 130 & 3 & 0,51 \\
SW902 & 3 & 65 & 4 & 0,57 & SW949 & X & 0 & 6 & 0,63 \\
S0002 & 3 & 112 & 7 & 0,79 & SW980 & X & 15 & 4 & 0,48 \\
SW717 & 3 & 134 & 4 & 0,63 & SW2126 & $X$ & 38 & 3 & 0,52 \\
SW2494 & 12 & 0 & 3 & 0,45 & SW1943 & X & 90 & 3 & 0,49 \\
SW957 & 12 & 24 & 6 & 0,64 & S0218 & $X$ & 120 & 3 & 0,38 \\
SW168 & 12 & 61 & 4 & 0,68 & & & & & \\
\hline
\end{tabular}

${ }^{1}$ SSC: Sus scrofa chromosome. ${ }^{2}$ Posição dos marcadores no cromossomo em cM 
A distância média entre os marcadores em algumas regiões dos cromossomos avaliados foi em torno de $30 \mathrm{cM}$, devido à dificuldade de se identificarem marcadores polimórficos nessas regiões na população de estudo. $\mathrm{Na}$ maioria dos cromossomos, os mapas de ligação estavam de acordo com o tamanho do mapa do USDA-ARS, considerado como referência (http://www.marc.usda.gov/genome/swine/swine .html).
Os limiares de significância para testar o modelo com efeito aditivo e de dominância, obtidos via teste de permutação em nível genômico, foram de 8,30 a 10,06 , respectivamente, a $5 \%$ e $1 \%$ para os cromossomos autossômicos; e de 13 e 16,35 para o cromossomo sexual. Foram identificados seis QTL associados a diferentes características de desempenho, sendo o QTL para idade ao abate no SSC3 significativo em nível genômico (Tab. 2).

Tabela 2. Estimativa da posição (POS), valores de F significativos (F), efeito aditivo (a) e de dominânica (d), desvio-padrão (DP), variância aditiva e intervalo de confiança (IC) para cada QTL

\begin{tabular}{cccccccc}
\hline SSC & Característica $^{1}$ & $\mathrm{~F}$ & $\mathrm{POS}^{2}$ & $\mathrm{a}^{3}(\mathrm{DP})$ & $\mathrm{d}(\mathrm{DP})$ & $\mathrm{h}_{\mathrm{q}}{ }(\%)^{4}$ & $\mathrm{IC}^{5}$ \\
\hline 1 & $\mathrm{CR}$ & $6,21^{*}$ & 102 & $1,89(0,94)$ & $-7,48(2,35)$ & 3,70 & $95-120$ \\
1 & $\mathrm{GPD}$ & $5,57^{*}$ & 93 & $0,04(0,01)$ & $-0,07(0,03)$ & 6,40 & $85-100$ \\
1 & $\mathrm{IDA}$ & $5,08^{*}$ & 68 & $-0,39(0,89)$ & $4,62(1,44)$ & 0,08 & $60-75$ \\
3 & $\mathrm{IDA}$ & $8,3^{* * *}$ & 10 & $3,74(1,00)$ & $-193(2,04)$ & 7,32 & $0-26$ \\
15 & $\mathrm{CR}$ & $5,45^{*}$ & 64 & $-0,30(0,54)$ & $2,52(0,77)$ & 0,10 & $50-73$ \\
$\mathrm{X}$ & $\mathrm{NT}$ & $7,28^{*}$ & 77 & $0,32(0,15)$ & $0,80(0,31)$ & 3,24 & $68-98$ \\
\hline
\end{tabular}

*,**, ***significativo a $5 \%\left(\mathrm{P}_{\mathrm{c}}<0,05\right)$ e $1 \%\left(\mathrm{P}_{\mathrm{c}}<0,01\right)$ em nível cromossômico e a $5 \%$ em nível genômico $(\mathrm{P}<0,05)$, respectivamente. ${ }^{1} \mathrm{CR}$ : consumo de ração dos 77 aos 105 dias de idade (kg); GPD: ganho de peso diário (kg); IDA: idade ao abate (dias) e NT: número de tetos. ${ }^{2}$ Posição em cM. ${ }^{3}$ Valores positivos dos efeitos aditivos indicam que os alelos da raça Piau causam aumento na característica avaliada.

${ }^{4}$ Fração aditiva da variância fenotípica $\left(\sigma_{\mathrm{y}}{ }^{2}\right)$ explicada pelo QTL $\left(\mathrm{h}_{\mathrm{q}}^{2}=\mathrm{a}^{2} / 2 \sigma_{\mathrm{y}}{ }^{2}\right) .{ }^{5}$ Intervalo de confiança em cM.

A deposição de gordura requer mais energia e nutrientes do que a deposição de proteína, assim alelos associados a um maior consumo de alimentos podem estar diretamente relacionadas à maior deposição de gordura. Isto foi confirmado neste trabalho, pois encontrou-se QTL para maiores CR $\left(\mathrm{a}=1,89 ; \mathrm{P}_{\mathrm{c}}<0,05\right)$ e GPD $(\mathrm{a}=0,04 ; \mathrm{Pc}<0,05)$ na região distal do $\mathrm{SSC} 1$, associados aos alelos da raça Piau, raça caracterizada por grande acúmulo de gordura subcutânea. Ainda, no SSC1 encontrou-se um QTL para maior idade ao abate associado aos alelos da linhagem comercial $(a=-0,39)$, o que não era esperado, uma vez que os animais de linhagem comercial, tipo carne, atingem o peso de abate antes dos animais Piau, tipo banha. Contudo, este QTL explicou muito pouco da variação fenotípica dessa característica $\left(h^{2} \mathrm{q}=0,08 \%\right)$.

O melhoramento genético baseia-se na variabilidade existente entre os animais. Segundo Cheng et al. (2000), estudos sobre polimorfismos de nucleotídeos (SNP) têm grande potencial para melhorar as características de desempenho como massa muscular, conversão alimentar e ganho de peso diário. De acordo com Kim et al. (2000), o receptor de melacortina (MC4R) exerce influência nas características de desempenho em suínos, particularmente na taxa de crescimento e no consumo alimentar, e os QTL para CR e GPD encontrados no presente estudo no SSC1 estariam localizados próximos da região do MC4R.

Os QTL para CR (intervalo de confiança: IC = 95-120) e GPD (IC = 85-100), localizados na posição distal do SSC1, entre os marcadores SWR942 e S0112, explicaram, respectivamente, 3,7 e $6,4 \%$ da variância fenotípica da característica. Assim como no presente trabalho, Sanchez et al. (2006) encontraram QTL para GPD na posição distal do SSC1 $(87 \mathrm{cM})$ ao estudarem uma população Meishan $x$ Large White. Beeckmann et al. (2003) encontraram QTL para CR a 117,2cM e 74,3cM e para GPD a 59,7cM, no SSC1 de suínos selvagens europeus x Pietrain. Liu et al. (2007) encontraram QTL 
Detecção de locos de características...

para GPD entre os marcadores SW1824 e SW1301, a 88,9cM no SSC1, o qual segregou em uma população Duroc x Pietrain.

A variação na localização do QTL para a mesma característica ou a ausência do QTL em diferentes populações se deve ao fato de que os estudos de mapeamento são feitos em populações com distintas composições genéticas e/ou diferentes marcadores. Assim, o alelo associado a um determinado QTL pode não estar em desequilíbrio de ligação com os marcadores avaliados nos diferentes estudos. Dessa forma, é necessário proceder à validação dos QTL detectados em populações experimentais antes de tais informações serem utilizadas em programas de seleção.
Na região proximal do SSC3 $(10 \mathrm{cM})$, encontrouse QTL genômico a $5 \%$ de probabilidade para idade ao abate, o qual explicou $7,32 \%$ da variação fenotípica da característica (Fig. 1), associado aos alelos da raça Piau. Tal resultado era esperado, pois o ganho de peso de animais tipo banha, como é o caso da raça Piau, é mais lento. Segundo Benevenudo Júnior (2001), ao estudar a presente população, os suínos Piau atingiram peso ao abate de $65 \mathrm{~kg}$ após sete meses de idade, enquanto os suínos da linhagem comercial atingiram o peso ao abate entre quatro e cinco meses. Outros estudos encontraram na região proximal do $\mathrm{SSC} 3$, região do presente QTL para idade ao abate, QTL para peso ao nascimento (Malek et al., 2001; Quintanilla et al., 2002; Liu et al., 2007).

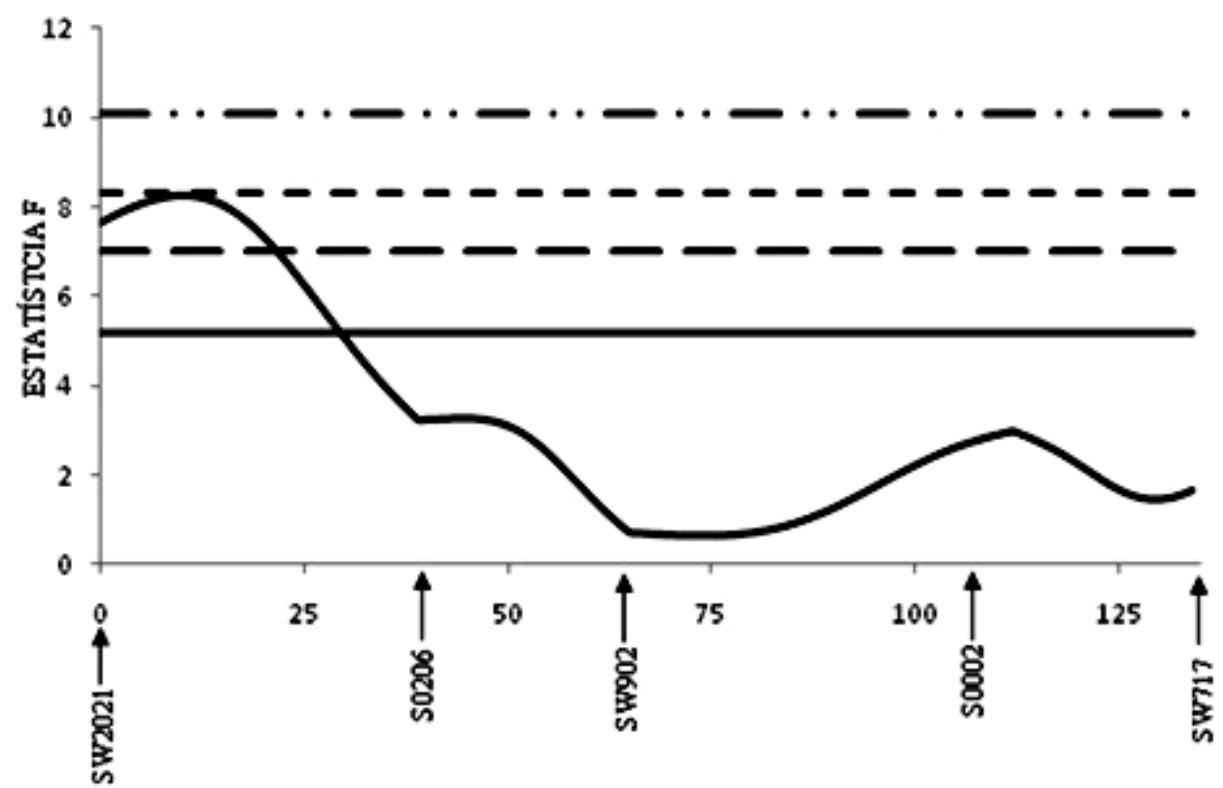

Figura 1. Estimativas dos valores de F para idade ao abate de suínos no SSC 3. Linhas horizontais indicam os níveis de significância ao longo do cromossomo: $5 \%$ cromossômico (-), $1 \%$ cromossômico (- -), $5 \%$ genômico (- - ) e $1 \%$ genômico (- .-). A posição dos marcadores é indicada por setas.

Na região central do $\mathrm{SSC} 15(64 \mathrm{cM})$, entre os marcadores SW1989 e SW1119, encontrou-se QTL cromossômico a 5\% de probabilidade para $\mathrm{CR}$, associado aos alelos da linhagem comercial, o qual explicou apenas $0,10 \%$ da variação fenotípica. Resultado semelhante foi encontrado por Liu et al. (2007), que detectaram QTL para consumo de ração no SSC15 com IC $=88,5$ - 119,9, o qual segregou em uma população Duroc x Pietrain, entre os marcadores
SW936-SW1119, e explicou 2,0\% da variação fenotípica. Já Houston et al. (2005) encontraram QTL para consumo de ração dos 35 aos $55 \mathrm{~kg}$ a 94,4cM e QTL para CR dos 35 aos 80kg a $83,1 \mathrm{cM}$, o qual segregou em uma população Meishan x Large White.

Identificou-se QTL cromossômico para NT a 5\% de probabilidade no cromossomo sexual X (Fig. 2), o qual explicou 3,24\% da variação fenotípica 
da característica e associado aos alelos da raça Piau. O número total de tetas é uma característica importante, uma vez que influencia o desempenho dos leitões durante a fase de prédesmama.

Faria et al. (2006) encontraram, nessa mesma população, associação significativa entre número de tetas e um polimorfismo detectado no gene do hormônio do crescimento (G316A). Vários estudos, empregando distintas populações de suínos, relataram a presença de QTL para número de tetas em diferentes cromossomos. Ding et al. (2009) o detectaram em população Duroc x Erhualian nos cromossomos 1, 3, 4, 5, 6, 7, 8 e 12; Sato et al. (2006), a partir de uma população Meishan x Duroc, detectaram-no no SSC7; e Beeckmann et al. (2003) no SSC8, o qual segregou em uma população de porco selvagem x Meishan.

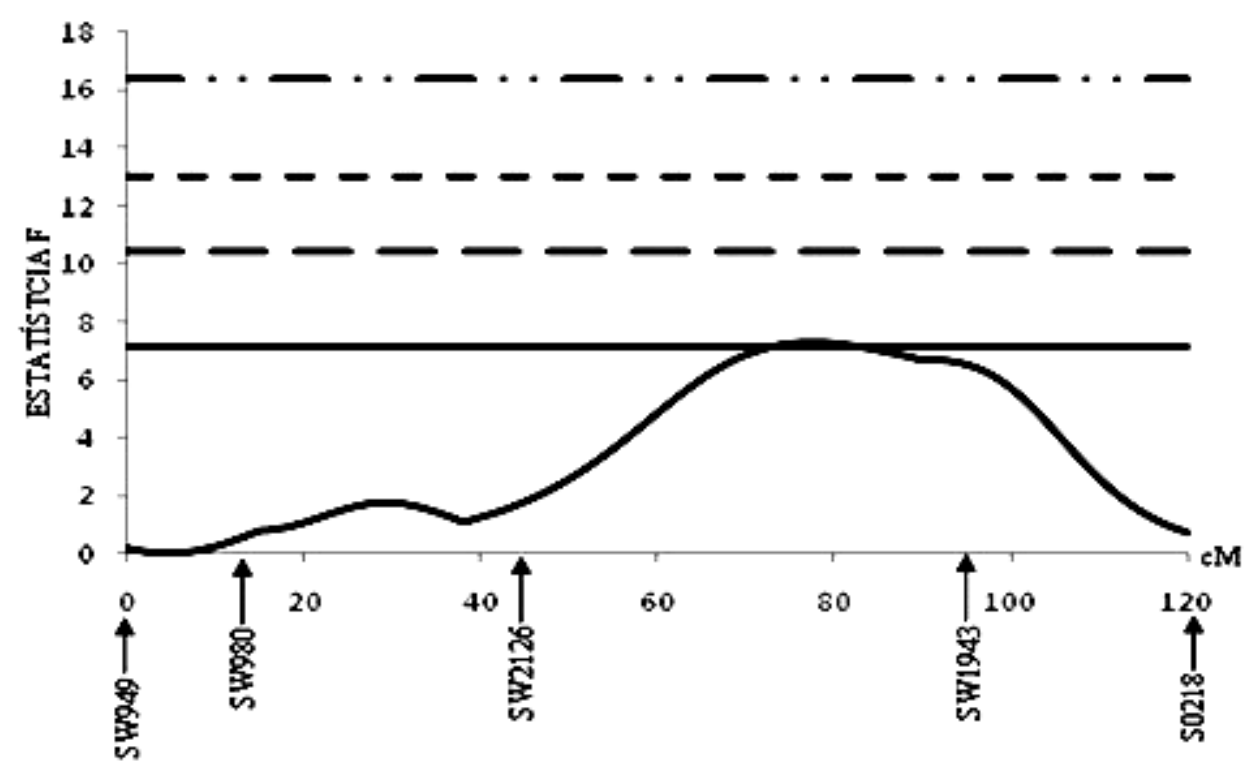

Figura 2. Estimativas dos valores de F para número de tetas (NT) no SSC X. Linhas horizontais indicam os níveis de significância ao longo do cromossomo: $5 \%$ cromossômico (-), $1 \%$ cromossômico (- -), 5\% genômico (- - -) e $1 \%$ genômico (- . -). A posição dos marcadores é indicada por setas.

\section{CONCLUSÕES}

Foram detectados QTL significativos para características de desempenho nos cromossomos 1, 3, 15 e X de suínos pertencentes a uma população derivada do cruzamento entre a raça Piau e uma linhagem comercial. O mapeamento fino dessas regiões será necessário para o melhor entendimento do efeito de cada QTL e a possível detecção de genes candidatos.

\section{AGRADECIMENTOS}

Ao Prof. Max F. Rothschild, coordenador do US Pig Genome Project, pela doação dos primers microssátelites.

\section{REFERÊNCIAS}

BEECKMANN, P.; SCHRÖFFEL, J. JR.; MOSER, G. et al. Linkage and QTL mapping for Sus scrofa chromosome 1. J. Anim.l Breed. Genet., v.120, p.1-10, 2003.

BENEVENUTO JR. A.A. Avaliação de rendimento de carcaça e de qualidade da carne de suínos comerciais de raça nativa e cruzados. 2001. 98f. Dissertação (Mestrado em Ciência e Tecnologia de Alimentos) - Universidade Federal de Viçosa, MG.

BOTSTEIN, D.; WHITE, R.L.; SKOLMICK, H. et al. Construction of a genetic linkage map in man using restriction fragment length polymorphism. Am. J. Hum. Genet., v.32, p.314331, 1980. 
CHENG, T.K.W.; LEE, C.H.; HUNG, C.M. et al. Growth hormone gene polymorphisms and growth performance traits in Duroc, Landrace and Tao-Yuan Pigs. Theriogenology, v.54, p.1225, 2000.

CHURCHILL, G.A.; DOERGE, R.W. Empirical threshold values for quantitative trait mapping. Genetics, v.138, p.963-971, 1994.

DING, N.; GUO, Y.; KNORR, C. et al. Genomewide QTL mapping for three traits related to teat number in a White Duroc $\mathrm{x}$ Erhualian pig resource population. BMC Genetics, v.10, p. 1-8, 2009.

FARIA, D.A.; GUIMARÃES, S.E.F.; LOPES, P.S. et al. Association between G316A growth hormone polymorphism and economic traits in pigs. Genet. Mol. Biol., v.29, p.634-640, 2006.

GILBERT, H.; RIQUET, J.; GRUAND, J. et al. Detecting QTL for feed intake traits and other performance traits in growing pigs in a PiétrainLarge White backcross. Animal, v.4, p.13081318, 2010.

GREEN, P.; FALLS, K.; CROOKS, S. Documentation for CRIMAP, St. Louis, Mo.: Washington Univ. School of Medicine, 1990. Disponível em: <http://linkage.rockefeller.edu/soft/crimap $>$. Acessado em: 20 abr. 2010.

GUIMARÃES, S.E.F.; LOPES, P.S. Uso de recursos genéticos nativos no mapeamento genético de suínos. Ação Ambiental, v.15, p.2728, 2001.

HALEY, C.S.; KNOTT, S.A.; ELSEN, J.M. Mapping quantitative trait loci in crosses between outbred lines using least squares. Genetics, v.136, p.1195-1207, 1994.

HOUSTON, R.D.; HALEY, C.S.; ARCHIBALD, A.L. et al. A QTL affecting daily feed intake maps to Chromosome 2 in pigs. Mamm. Genome, v.16, p.464-470, 2005.

KALINOWSKI, S.T.; TAPER, M.L.; MARSHALL, T.C. Revising how the computer program CERVUS accommodates genotyping error increases success in paternity assignment. Mol. Ecol., v.16, p.1099-1006, 2007.
KIM, K.S.; LARSEN, N.; SHORT, T. et al. A missense variant of the porcine melanocortin-4 receptor (MC4R) gene is associated with fatness, growth, and feed intake traits. Mamm. Genome, v.11, p.131-135, 2000.

KNOTT, S.A.L.; MARKLUND, C.S.; HALEY, K. et al. Multiple marker mapping of quantitative trait loci in a cross between outbred wild boar and Large White pigs. Genetics, v.149, p.10691080, 1998.

LIU, G.; JENNEN, D.G.J.; THOLEN, E. et al. A genome scan reveals QTL for growth, fatness, leanness and meat quality in a Duroc-Pietrain resource population. Anim. Genet., v.38, p.241252, 2007.

MALEK, M.; DEKKERS, J.C.M.; LEE, H.K. et al. A molecular genome scan analysis to identify chromosomal regions influencing economic traits in the pig. II. Meat and muscle composition. Mamm. Genome, v.12, p.637-645, 2001.

MILLER, S.A.; DYKES, D.D.; POLESKY, H.F. A simple salting out procedure for extracting DNA from human nucleated cells. Nucleic Acids Res., v.16, p.1215, 1988.

PAIXÃO, D.M.; SILVA FILHO, M.I.; PEREIRA, M.S. et al. Quantitative trait loci for carcass, internal organ and meat quality traits on porcine chromosomes 16, 17 and 18. Genet. Mol. Biol., v.31, p.898-901, 2008a.

PAIXÃO, D.M.; GUIMARÃES, S.E.F.; SILVA FILHO, M.I. et al. Detecção de locos de características quantitativas nos cromossomos 16, 17 and 18 de suínos. Rev. Bras. Zootec., v.37, p.1781-1787, 2008b.

PÉREZ-ENCISO, M.; CLOP, A.; NOGUERA, J.L. et al. A QTL on pig chromssome 4 affects fatty acid metabolism: Evidence from Iberian by landrace intercross. J. Anim. Sci., v.78, p.25252531, 2000.

PIRES, A.V.; LOPES, P.S., GUIMARÃES, S.E.F. et al. Quantitative trait loci mapping for meat quality traits in swine chromosome 6. Arq. Bras. Med. Vet. Zootec., v.57, p.608-615, 2005.

QUINTANILLA, R.; MILAN, D.; BIDANEL, J.P. A further look at quantitative trait loci affecting growth and fatness in a cross between Meishan and Large White pig populations. Genet. Sel. Evolut., v.34, p.193-210, 2002. 
SANCHEZ, M.P.; RIQUET, J.; IANNUCCELLI, N. et al. Effects of quantitative trait loci on chromosomes 1, 2, 4, and 7 on growth, carcass, and meat quality traits in backcross Meishan X Large White pigs. J. Anim. Sci., v.84, p.526-37, 2006.

SATO, S.; ATSUJI, K.; SAITO, N. et al. Identification of quantitative trait loci affecting corpora lutea and number of teats in a Meishan $x$ Duroc F2 resource population. J. Anim. Sci., v.84, p.2895-2901, 2006.

SEATON, G., J. HERNANDEZ, J. A. GRUNCHEC, I. WHITE, J. ALLEN et al., 2006 GridQTL: A Grid Portal for QTL Mapping of Compute Intensive Datasets. Proceedings of the 8th World Congress on Genetics Applied to Livestock Production, August p.13-18, 2006. Belo Horizonte, Brazil.
SILVA, K.M.; PAIXÃO, D.M.; SILVA, P.V. et al. Mapping of quantitative trait loci and confirmation of the FAT1 region on chromosome 4 in an F2 population of pigs. Genet. Mol. Biol., v.31, p.475-480, 2008.

TÔRRES, A.D.P. Suínos: Manual do criador. Biblioteca Agronômica Melhoramentos. São Paulo: Edições Melhoramentos, 1968. 428p. 